\title{
Try on a new pair of sensible shoes What libraries can learn from Zappos about customer service and organizational culture
}

A cademic libraries can improve relationships and increase their reputation on campus by adapting customer service philosophies based on trends in the business world, speci cally, the core values championed by thriving online shoe retailer Zappos. ${ }^{1}$ The current economic downturn can spread a bleak mood across campus. Graduating seniors grasp the burden of repaying student loans in a job market that reached an 8.5 percent unemployment rate. Faculty, staff, and administrators recall Depression-era advice from their parents and grandparents as they grapple for ways to do more with less. But now is the time to strengthen the library s customer service expertise and serve our campus communities information needs by offering compassion, commiseration, and a little extra kindness that is modeled by the ten core values from which Zappos operates.

Dubbed the Amazon of shoes, Zappos distinguished itself from other online shoe retailers in courting, and, more importantly, keeping customers by offering free shipping on purchases and returns, which makes customers happy about ordering multiple sizes to get a perfect- tting product. Its 365-day return policy also creates complete customer satisfaction because customers appreciate the company s long-term commitment to them, and the automatic VIP upgrade that includes next-day shipping is an unexpected perk.

Excellent customer service, combined with leadership from their Gen X CEO Tony Hsieh and the thriving organizational culture at Zappos, join together, further cementing its success. The company s emphasis on customer service and its loyalty to employees are why their call center operations have not been outsourced, a strategy businesses use to cut rising personnel costs. Further, Zappos call center workers sail through the retail transaction unscripted; their record for longest customer phone call is four hours. ${ }^{2}$ Both features, improvised conversations, and locally based call centers are rarities in our increasingly globalized economy.

These business strategies, along with its admirable customer service, allowed Zappos to ourish while other online shoe retailers folded in an increasingly competitive online retail environment.

But what does the price of shoes have to do with libraries? Everything, really. Zappos operates from ten core values that can be customized to any library s footprint. ${ }^{3}$ Many of Zappos core values are not novel, nor will they be alien to librarians. However, they are shared here to uplift morale, which may in turn stir conversations about service and organizational culture and boost library service practices with Zappos spirit and enthusiasm within academic libraries.

1. Deliver Wow through service. Go above and beyond to differentiate the quality of service users receive in the library from other departments on campus, as well as from competitors off campus, such as cafes, bookstores, and the public library. Students

Rebecca Tolley-Stokes is reference librarian at East Tennessee State University, e-mail: tolleyst@etsu.edu

๑ 2009 Rebecca Tolley-Stokes 
encounter roadblocks in of ces and other departments on campus whose staffs are not trained to answer questions, cultivate ownership of problems, or empowered to follow a project or problem through to its resolution. Add unconventional and innovative components to library outreach, such as reference service at the university s gymnasium, where daily gatecounts outnumber the library s. Positive experiences are key to generating return visits to the library. Academic librarians recognize the ne line between showing students how to access information and completing assignments for them. We keep the adage about teaching a person to sh as opposed to handing the person a sh in mind as we approach students.

Maintain the boundary, but leave the student with an emotional impression, your name and e-mail for follow-up, a personal connection concerning a sports team, restaurant, or book. If it is raining outside, demonstrate your compassion and offer the student your umbrella, along with your business card so they can return the item on the next dry day. How does the library patron feel at the end of the transaction? Ask. Consider this a reminder of the Maryland Model of Reference Interview that many of us learned in library school, but are often too harried to summon each day.

2. Embrace and drive change. As with every profession, there are librarians alert to changes within the profession and technology, and those who are not. Keeping abreast of new databases, or trends in social networking, improves the timeliness and quality of service. Change emerges from the bottom up at Zappos, and is driven by employees working in concert with customers. Those immediate, one-on-one interactions are the basis of creating relationships between clients and organizations. Zappos focus on extreme customer satisfaction allows it to rocket ahead of competition and provides a rehabilitated model of customer service. Regularly consult with library staff and student workers for their insights about improvements to library services and outreach.

\section{Create fun and a little weirdness.} Even today, with scores of chic, sociable people drawn into the profession, old stereotypes persist. Do not seem dour, unapproachable, and boring. Laugh and smile; inject humor into the library and into your relationships. Organizational culture, which celebrates and embraces the diversity of each person, makes Zappos successful. Zappos employees don costumes and parade across the call center oor to spark team spirit and motivate workers as the day progresses. They collaborate to create videos to cheer up co-workers and to persuade celebrities, such as Ellen DeGeneres, to visit the Zappos team. ${ }^{4}$ Then the videos are shared on YouTube and Facebook for broader distribution and appreciation. Zappos team verve and sentiments are viral. Though book cart drill teams are often the province of public librarians and SLIS students, forming a group and offering exhibition performances across campus is one way to demonstrate both air and fun happening in the library.

4. Be adventurous, creative, and open-minded. Leap into a new service or outreach area to learn fresh skills. We learn little from business as usual, and that is why a different set of challenges energize organizations. Explore possibilities like blogging, Twitter, Facebook, and other forms of social media to connect with students before they become ubiquitous and pass . Be an early adopter or adapter of new media. Instead of handing out paper business cards to students, as suggested in the rst core value, text your business card information to students via Contxts, which uses SMS (Short Message Service) technology to exchange and organize professional information by cell phone.

5. Pursue growth and learning. Traditional types of professional development, conference attendance, and continuing education are critical for librarians and library staff. Cross boundaries and nose about for trends in public and special libraries 
easily adapted to academic libraries. Look for opportunities to update your skills, for example, by turning an empty space into a playground, where library faculty and staff have fun with digital equipment and software that they may not be using in their personal lives for nancial or other reasons. They gain step-by-step knowledge of creating content and thus empowered, can troubleshoot questions students encounter as they use technology within assignments.

6. Build open and honest relationships with communication. Connect with library users across platforms, both in person and online, and then communicate. Offer regular library content. Introduce students to Twitter and recommend they tweet during a LI/BI session so that you have immediate and honest assessment of your teaching effectiveness by way of Twitter s instant feedback loop. This style of transparency is a daring move, but one that endows students with control, your trust, and a vested interest in the session.

7. Build a positive team and family spirit. From the start, Zappos conscientiously builds teams via strict hiring and training practices, which are key in creating and sustaining the organizational culture that spawns excellence in customer service. Potential employees are carefully questioned, trained, and offered a $\$ 2,000$ incentive to quit in the rst few weeks so that they do not adversely affect the team $s$ vibe. ${ }^{5}$ With applicants for vacant librarian positions numbering in the hundreds, there is no reason that libraries cannot bene $t$ from the abundance of applicants and select candidates who impart optimism and innovation.

Bolster your networks with novel forms of communication. Connect with your colleagues outside of the library the old fashioned way with a weekly lunch or coffee klatch, as well as by using social media. Exchanges outside the of ce can kindle novel ideas because stress levels are reduced, guards are down, and attitudes are cheerful outside of the of ce. Managers at Zappos are encouraged to spend 10 to 20 percent of their personal time with workers outside the call center.

At Zappos employees reward each other with $\$ 50$ bonuses for a job well done. ${ }^{6}$ When one worker is impressed by the creativity or altruism of another, they submit a request citing the reason their co-worker awed them via their software. Once approved by their manager, the nominee prints, decorates, and gives it to the person who impressed them. The award winner sees the $\$ 50$ in their next paycheck. $^{7}$

Zappos employees develop strong relationships and emotional connections with their team and the CEO by using Twitter and Facebook as part of their daily work ow. Librarians cannot give one another $\$ 50$ bonuses, but how often do we nominate one another for awards? Make it a point to recommend your colleagues for institutional, regional, and national awards to show your appreciation for their outstanding performance. Funds occasionally accompany this sort of award.

Experiment with Twitter in your library by having library staff and faculty tweet to each other about current trends in libraries or areas of personal interest, such as favorite comic books, local restaurants, or tourist attractions.

8. Do more with less. Zappos functions from a basis of operational excellence by promoting ef ciency and nding the best way to do business. One area, at least, may disturb librarians organizational orientation: Zappos warehouse is completely disorganized. ${ }^{8}$ After experimenting with various methods of classifying shoes by make, model, or season, Zappos abandoned organizational schemes for UPC logging. Once a box of shoes enters the warehouse, its UPC label is scanned and its location is logged. As far as inventory control systems go, it works in a warehouse situation and might in closed stacks, but is not recommended for academic libraries.

9. Be passionate and determined. Zappos workers share a consistent vision and purpose. Their organizational culture 
converges at the goal of nessing customer service.

Revisit your library s organizational principles namely its mission, goals, and objectives to remind everyone of common aims. Hire people who love libraries, who love helping, who love service. List ten things you like about your library, or your job, or the profession, and select one or two of those items to focus upon. Cultivate passion by mingling with positive people in allied elds with whom you can share information and foster creative collaborations. Apply expertise from a hobby or interest to a project or program and revive your passion.

10. Be humble. Zappos distills humility into displaying quiet con dence, treating others how we want to be treated, and never being arrogant. Granted, librarians are noble, humble, and long-suffering according to the stereotype, but being humble affects our ability to promote ourselves, our libraries, and our profession. Our habitual deference served as a character defect and resulted in our low position in the hierarchy of information professionals. Our quietude has not served the profession or our pro le on campus. This core value is one librarians internalize to our detriment and is not recommended.

A regular review of scholarly communication in librarianship reveals frequent missives regarding enhancing customer service by revamping the library s organizational culture. Such reminders are useful as a reframing of the topic may ultimately capture a reader s notice, sink in, and effect change.

Zappos ten core values include worthy ideas for consideration in improving both the quality of customer service and imperfect aspects of the organizational culture of libraries. Use these ideas, or expand upon them, to improve practices and to reshape your library s culture, so all can ful 11 the shared goals and purposes of your library. Spending four hours answering a single reference question, or any service transac- tion in a library, for that matter, is simply not viable for our service desks.

We lack funding to encourage one another with $\$ 50$ bonuses, but the most important lessons to draw from Zappos are not about monetary rewards, but about complimentary improvements to customer service and your organizational culture.

\section{Notes}

1. C. A. Chouteau, et. al., Gone Fishing: Using the FISH! Business Model to Motivate Student Workers, Technical Services Quarterly 24, no. 3 (2007): 41 9, Linda C. Brown and Benjamin Layne, Lessons From the Ice Cream Parlor: Four Goals to Improve Customer Service and Individual Attitudes, AALL Spectrum 9, no. 6 (April 2005): 6-7, Mark B. Bernstein, How Customer Service Principles Ensure the Library s Relevance, AAAL Spectrum 13 no 2. (November 2008): 2122.

2. www.facebook.com/pages /Zapposcom/7172307686? $\mathrm{ref}=\mathrm{ts} \& \# /$ video /video.php?v=66809307641\&ref=mf.

3. about.zappos.com/our-unique-culture /zappos-core-values.

4. www.facebook.com/video/video. php?v=691555155769.

5. Keith McFarland, Why Zappos Offers New Hires \$2,000 to Quit; The Policy of Providing a Let-Out After One Week Has Gained Worldwide Attention, Business Week Online, September 17, 2008, www. businessweek.com/smallbiz/content /sep2008/sb20080916_288698.htm. Accessed March 21, 2009.

6. J. M. O Brien, Zappos Knows How to Kick It [Part of a special section on the 100 Best Companies to Work For; cover story], Fortune v. 159 no. 2 (February 2 2009): 54 6, 58, 60

7. Conversation with Jenna, Zappos customer service representative March 24, 2009.

8. www.longtail.com/the_long_ tail/2007/01/everything_is_m.html. Accessed March 21, 2009. z 